\title{
Wat gebeurt er met resultaten van onderzoek van onderwijs in de onderwijspraktijk?
}

\author{
N. Hylkema, C.J.A.H. Prince, C.P.M. van der Vleuten, A.J.J.A. Scherpbier
}

\section{Samenvatting}

Inleiding: Het medisch onderwijs is overal in beweging'. Curricula worden veranderd. Er zijn congressen en tijdschriften alleen over medisch onderwijs. Internationaal wordt bepleit om de discussie over onderwijs meer te baseren op 'evidence'. Wij vroegen ons af hoe belangrijk de resultaten van onderzoek van onderwijs zijn en hoe men op de hoogte blifft van de ontwikkelingen.

Methode: Een schriftelijke enquête werd verzonden aan 326 personen die een functie hebben in de gremia waar onderwijsbesluiten worden genomen in de acht medische faculteiten. Na vier weken werd schriftelijk gerappelleerd.

Resultaten: De respons bedroeg 74.2\%. Lokale cursussen worden vaak bezocht. Landelijke en internationale congressen worden minder vaak bezocht. Tijdschriften worden zelden gelezen en de namen zijn zelfs voor een groot deel van de respondenten onbekend. Onderzoek van onderwijs wordt wel belangrijk gevonden.

Conclusie: De mogelijkheden om op de hoogte te blijven van recente ontwikkelingen kunnen en moeten veel beter benut worden. (Hylkema $N$, Prince CJAH, Vleuten CPM van der, Scherpbier AJJA. Wat gebeurt er met resultaten van onderzoek van onderwijs in de onderwijspraktijk? Tijdschrift voor Medisch Onderwijs 2001;20(1):2-7.)

\section{Inleiding}

Het medisch onderwijs is de afgelopen jaren overal in 'beweging'. De faculteiten geneeskunde hebben hun curriculum grondig herzien of zijn hiermee bezig. Hoewel elke faculteit eigen accenten legt, is er bij alle vernieuwingen sprake van een verschuiving van docentgecentreerd naar studentgecentreerd onderwijs. Tussen de faculteiten vindt heel open overleg plaats over onderwijs. Men gaat bij elkaar op bezoek, gebruikt elkaars onderwijsmateriaal, et cetera. Het Gezond Onderwijs Congres (GOC) is een jaarlijks goed bezochte bijeenkomst geworden, die zich kan 'meten' met internationale onderwijscongressen. Het Bulletin Medisch Onderwijs is uitgegroeid tot het Tijdschrift voor Medisch Onderwijs (TMO). Internationaal is het medisch onderwijs ook in 'beweging'. Er zijn bijvoorbeeld internationale con- gressen en tijdschriften die alleen over medisch onderwijs gaan. Het gaat dus best goed met het medisch onderwijs, maar het kan (en moet) nog beter.

Veel discussies over onderwijs, zowel internationaal als nationaal, zijn namelijk nog gebaseerd op eigen onderwijservaringen van docenten, opinies die in bepaalde omgevingen bestaan, ervaringen van de kinderen van docenten. Kortom, onderwijsbeslissingen lijken nog steeds meer 'opinion based' dan 'evidence based' en uitkomsten van onderzoek van onderwijs lijken zelden een rol te spelen. Internationaal wordt bepleit dat we moeten streven naar 'Best Evidence Medical Education' (BEME). ${ }^{1}$ Dit streven wordt in zijn algemeenheid positief ondersteund, wellicht mede omdat je er ook nauwelijks tegen kunt zijn. De vraag is of er ook aantoonbaar meer aandacht is voor 'evidence' in de echte onderwijsprak- 
tijk. Uit een onderzoek in de Verenigde Staten in 1990 bleek dat er onder hoogleraren weinig tot geen kennis bestond over resultaten van onderzoek van onderwijs. ${ }^{2}$ In 1999 bleek uit een kwalitatief onderzoek in Nederland dat ook bij ons resultaten van onderzoek van onderwijs zelden een rol spelen bij beleidsbeslissingen over onderwijs. ${ }^{3}$ Voor dit laatste onderzoek werden twintig 'onderwijsmensen' telefonisch geënquêteerd. Er kan dus sprake geweest zijn van selectie. Om na te gaan of de bevindingen uit de telefonische enquête generaliseerbaar zijn, is een kwantitatief onderzoek verricht met als vraagstelling: Hoe belangrijk zijn de resultaten van onderzoek van onderwijs en hoe blijft men op de hoogte van recente ontwikkelingen?

\section{Methode}

\section{Proefpersonen}

De geënquêteerden waren afkomstig uit faculteitsbestuur (of raad van bestuur), onderwijsinstituut, opleidingscommissie, examencommissie, faculteitsraad en curriculumherzieningscommissie (indien aanwezig). Deze gremia zijn gekozen omdat daar besluiten over onderwijs worden genomen. Uit de studiegidsen van de acht medische faculteiten werden de betreffende namen opgezocht en de zo verkregen lijst is per faculteit door een contactpersoon gecontroleerd en eventueel gecorrigeerd en/of aangevuld. De enquête werd toegezonden aan 326 personen en na vier weken werd, zo nodig, een herinneringsbrief opgestuurd.

\section{Instrument}

De enquête die in het eerdere onderzoek telefonisch werd afgenomen, is aangepast en aangevuld tot tien vragen. Via de eerste twee vragen werd informatie over de functie en positie van de respondent verzameld. Vervolgens werden vragen gesteld over congresbezoek, deelname aan cursussen op het gebied van medisch onderwijs en functies als docent bij deze cursussen. Ook werd aan de respondenten gevraagd of ze het Bulletin Medisch Onderwijs (de voorganger van TMO) en zeven internationale tijdschriften op het gebied van medisch onderwijs kenden. Op een vijfpuntsschaal kon worden aangegeven hoe vaak de tijdschriften werden gelezen. Het belang van onderzoek van onderwijs, het belang van verschillende factoren (externe maatregelen, financiële mogelijkheden, onderzoeksresultaten en eigen onderwijservaring) en de algemene houding ten aanzien van onderzoek van onderwijs werden door de respondenten op een vijfpuntsschaal ( 1 = niet belangrijk; 5 = heel belangrijk) aangegeven.

\section{Dataverwerking}

De enquêtes werden ingevoerd in SPSS en beschrijvende statistiek werd uitgedraaid.

\section{Resultaten}

Van de 326 verstuurde enquêtes werden er 242 teruggestuurd (respons 74.2\%). Er was voldoende respons uit alle gremia (tabel 1) om de gegevens uit te kunnen splitsen. Ongeveer een kwart van de respondenten was student.

Tabel 1. Aantal respondenten per gremium met tussen haakjes het percentage van het totaal.

\begin{tabular}{lrr} 
Faculteitsbestuur & 25 & $(10.3)$ \\
Onderwijsinstituut & 65 & $(26.9)$ \\
Opleidingscommissie & 58 & $(24.0)$ \\
Examencommissie & 39 & $(16.1)$ \\
Faculteitsraad & 25 & $(10.3)$ \\
Curriculumherzienings- & & \\
commissie & 24 & $(9.9)$ \\
Anders & 6 & $(2.5)$ \\
Totaal & 242 & \\
\hline
\end{tabular}


Tabel 2. Gegevens over congres- en cursusbezoek in percentages van het aantal respondenten.

\begin{tabular}{lrl}
\hline & Ja & Nee \\
\hline Lokale onderwijsdagen/symposia & 73.8 & 26.2 \\
Gezond Onderwijs Congres & 45.2 & 54.8 \\
Ottawa Conference & 4.6 & 95.4 \\
Lokale cursussen & 39.3 & 60.7 \\
Cursussen Specialisatie Medisch Onderwijs & 19.4 & 80.6 \\
\hline
\end{tabular}

De gegevens over congres- en cursusbezoek zijn weergegeven in tabel 2. Lokale onderwijsdagen en symposia worden door drie kwart van de respondenten bezocht, het minst vaak door leden van de faculteitsraad. Bijna de helft bezoekt het landelijke jaarlijkse Gezond Onderwijs Congres. Medewerkers van onderwijsinstituten en leden van curriculumherzieningscommissies bezoeken dit congres het vaakst en leden van examencommissie en faculteitsraad het minst vaak. Het Ottawa-congres, een internationaal congres dat elke twee jaar wordt georganiseerd, wordt door een zeer beperkt aantal respondenten $(4.6 \%)$ bezocht. Dit zijn met name medewerkers van onderwijsinstituten. De landelijke cursussen die voor docenten worden georganiseerd door de stichting ODOS in het kader van de Specialisatie Medisch Onderwijs worden door ongeveer een vijfde van de respondenten bezocht, met name medewerkers van onderwijsinstituten en leden van curriculumherzieningscommissies. Het aantal respondenten dat cursussen over medisch onderwijs geeft, is beperkt. Tien procent van de respondenten is als docent betrokken bij landelijke cursussen en $7 \%$ bij internationale cursussen.

Het bijwonen van congressen en het volgen van cursussen is een manier om op de hoogte te blijven van de ontwikkelingen. Een andere manier is het lezen van artikelen in tijdschriften. De antwoorden op een vraag in de enquête hierover zijn weergegeven in tabel 3. Het Bulletin Medisch Onderwijs is bij een kwart van de respondenten onbekend. De internationale tijdschriften zijn onbekend bij de helft tot drie kwart van de respondenten. Ruim een derde van de respondenten leest het Bulletin Medisch Onderwijs regelmatig.

Tabel 3. Per tijdschrift is het percentage respondenten weergegeven dat het tijdschrift niet kent en het percentage dat het tijdschrift tussen nooit (1) en altijd (5) leest.

\begin{tabular}{lcrrrrr}
\hline & Tijdschrift & \multicolumn{2}{c}{ Lees ik nooit } & \multicolumn{3}{c}{ Lees ik altijd } \\
& onbekend & \multicolumn{1}{c}{1} & \multicolumn{1}{c}{2} & \multicolumn{1}{c}{3} & \multicolumn{1}{c}{4} & \multicolumn{1}{c}{5} \\
\hline Bulletin Medisch Onderwijs & 24.7 & 7.9 & 14.6 & 16.1 & 12.1 & 25.5 \\
Academic Medicine & 61.5 & 18.6 & 10.8 & 3.0 & 3.0 & 3.0 \\
Medical Education & 51.7 & 18.4 & 14.1 & 8.5 & 4.3 & 3.0 \\
Medical Teacher & 58.4 & 18.9 & 12.9 & 4.3 & 3.9 & 1.7 \\
Teaching and Learning in Medicine & 64.2 & 21.4 & 10.0 & 2.6 & 1.3 & 0.4 \\
Advances in Health Sciences Education & 69.6 & 22.2 & 4.8 & 2.2 & 0 & 1.3 \\
Evaluation and the Health Professions & 73.8 & 22.2 & 4.8 & 0.9 & 0 & 0.4 \\
Education for Health & 73.2 & 18.6 & 4.8 & 3.0 & 0 & 0.4 \\
\hline
\end{tabular}


Tabel 4. De belangrijkheid van onderzoek van onderwijs aangegeven door de respondenten op een vijfpuntsschaal. Bij elk van de vijf schaalpunten staat het percentage respondenten, uitgesplitst per gremium, dat de betreffende score toekende.

\begin{tabular}{lccccc}
\hline & Niet belangrijk & & & \multicolumn{2}{c}{ Heel belangrijk } \\
& 1 & 2 & 3 & 4 & 5 \\
\hline Faculteitsbestuur & - & - & 12.0 & 48.0 & 40 \\
Onderwijsinstituut & - & - & 12.3 & 33.8 & 53.8 \\
Opleidingscommissie & - & - & 6.9 & 46.6 & 46.6 \\
Examencommissie & 2.6 & 7.7 & 23.1 & 46.2 & 20.5 \\
Faculteitsraad & - & - & 24.0 & 52.0 & 24.0 \\
Curriculumherzieningscommissie & - & - & 12.5 & 43.8 & 41.7 \\
\hline
\end{tabular}

Het lezen van internationale literatuur over medisch onderwijs blijkt ongebruike lijk te zijn. De respondenten die wel internationale tijdschriften lezen, zijn meestal verbonden aan een onderwijsinstituut, maar ook daar is het ongewoon.

In alle gremia wordt onderzoek van onderwijs belangrijk gevonden (tabel 4). Op een vijfpuntsschaal (van 1 = niet belangrijk tot 5 = heel belangrijk) wordt frequent 4 en 5 ingevuld. Respondenten uit de examencommissie en de faculteitsraad vinden onderzoek van onderwijs relatief minder belangrijk dan respondenten uit de andere gremia. Bij besluiten over medisch onderwijs spelen naast onderzoeksresultaten ook andere factoren een rol. De respondenten hebben de belang- rijkheid van een aantal factoren aangegeven op een vijfpuntsschaal (van 1 = niet belangrijk tot 5 = heel belangrijk). In tabel 5 is de som van de percentages respondenten die 4 en 5 hebben ingevuld per gremium weergegeven. Alle factoren worden belangrijk gevonden. Opvallend is dat onderzoeksresultaten in alle gremia erg belangrijk worden gevonden. Uit de antwoorden op de laatste vraag blijkt dat ongeveer de helft van de respondenten van mening is dat binnen de eigen instelling onderzoek van onderwijs belangrijk wordt gevonden.

\section{Beschouwing}

De respons op de enquête was goed. Het gegeven dat een kwart van de responden-

Tabel 5. Het belang dat respondenten hechten aan verschillende factoren bij besluiten over medisch onderwijs. Per gremium zijn de percentages respondenten die 4 en 5 invulden op een vijfpuntsschaal (1= niet belangrijk; $5=$ heel belangrijk) bij elkaar opgeteld.

\begin{tabular}{lllll}
\hline & $\begin{array}{l}\text { Externe } \\
\text { factoren }\end{array}$ & $\begin{array}{l}\text { Financiële } \\
\text { mogelijkheden }\end{array}$ & $\begin{array}{l}\text { Onderzoeks- } \\
\text { resultaten }\end{array}$ & $\begin{array}{l}\text { Eigen onderwijs- } \\
\text { ervaring }\end{array}$ \\
\hline Faculteitsbestuur & 56 & 60 & 72 & 54.2 \\
Onderwijsinstituut & 66.1 & 59.7 & 77.4 & 73.8 \\
Opleidingscommissie & 55.4 & 41.1 & 80 & 82.1 \\
Examencommissie & 61.1 & 58.3 & 77.8 & 83.8 \\
Faculteitsraad & 52 & 48 & 80 & 68 \\
Curriculumherzieningscommissie & 60.9 & 43.5 & 75 & 79.2 \\
\hline
\end{tabular}


ten student is, is een uiting van de (terecht) belangrijke rol van studenten in de facultaire organisatie. ${ }^{4}$ Onderzoek van onderwijs wordt door de respondenten uit alle gremia heel belangrijk gevonden. Bij beslissingen over onderwijs blijken onderzoeksresultaten een belangrijke rol te spelen. Het is niet duidelijk of en in hoeverre er sociaal wenselijke antwoorden zijn gegeven op deze vragen. Hoe het ook zij, het lijkt erop dat we wat betreft het belang van onderzoek van onderwijs in Nederland op de goede weg zijn. Er is echter ook nog wel wat te verbeteren. Lokale onderwijsdagen en symposia worden goed bezocht. Het Gezond Onderwijs Congres wordt slechts door bijna de helft van de respondenten bezocht en het Ottawa-congres wordt nauwelijks bijgewoond. Er zijn natuurlijk ook nog andere internationale onderwijscongressen, maar die worden ook maar door een beperkt aantal (meestal dezelfde) Nederlanders bijgewoond. Landelijke cursussen worden slechts door een klein deel van de respondenten bezocht, waarbij ongeveer de helft ook nog docent is. Deze mogelijkheden om bij te blijven en op de hoogte te zijn van recente ontwikkelingen worden dus maar in beperkte mate benut.

Een andere manier om op de hoogte te blijven is het bijhouden van de literatuur. Het Bulletin Medisch Onderwijs is voor een kwart van de respondenten onbekend. Voor de internationale tijdschriften is het beeld nog veel somberder. De helft tot drie kwart van de respondenten geeft aan zelfs de namen van de tijdschriften niet te kennen. Dit betekent dat het onwaarschijnlijk is dat er, in plaats van het lezen van tijdschriften, gerichte elektronische zoekacties plaatsvinden. Respondenten die de tijdschriften wel kennen, lezen er maar zelden in. Het is natuurlijk de vraag of men in alle gremia even goed op de hoogte moet zijn. Het is te verdedigen dat leden van het faculteitsbestuur en de faculteitsraad wat minder op de hoogte hoeven te zijn dan leden van de opleidings- en examencommissies. Dat betekent overigens wel dat er bij besluiten over onderwijs geluisterd zou moeten worden naar medewerkers die wel op de hoogte zijn. Los van bovenstaande overweging kan in zijn algemeenheid uit de resultaten geconcludeerd worden dat onderzoek van onderwijs wel belangrijk wordt gevonden, maar dat de mogelijkheden om goed op de hoogte te zijn, beter benut moeten worden. Het is goed voorstelbaar dat deze bevindingen een uiting zijn van het feit dat er tegenwoordig nu eenmaal prioriteiten in de drukke agenda's gesteld moeten worden. Of anders geformuleerd, kennelijk is er maar een beperkt aantal mensen in Nederland dat die prioriteit aan deze activiteiten geeft. Anderen moeten hun prioriteiten klaarblijkelijk elders leggen, ondanks het feit dat zij onderzoek van onderwijs wel belangrijk vinden. Het is positief dat er wel al prioriteit gegeven wordt aan de ontwikkeling van onderwijs, gezien de veranderingen in de curricula van alle faculteiten. Meer prioriteit voor onderzoek van onderwijs is een logische volgende stap. Zowel het onderzoeken van de effecten van verbeteringen als het toepassen van resultaten van elders verricht onderzoek, verdient meer aandacht en dus tijd. Als docenten meer tijd aan onderwijs moeten kunnen besteden, moet 'onderwijs' belangrijker worden dan het nu is. Onderwijs moet gezien worden als een van de drie academische taken en dus gelijkwaardig worden aan onderzoek en patiëntenzorg. Dit is ook van belang om ervoor te zorgen dat de curriculumverbeteringen, ook na het enthousiasme van de 'beginners', stand houden en om het onderwijs verder te verbeteren door aan te sluiten bij de ontwikkeling van Best Evidence Medical Education. ${ }^{1}$ 


\section{Literatuur}

1. Harden RM, Grant J, Buckley G, Hart IR. BEME Guide no. 1: Best evidence medical education.

Med Teach 1999;216:553-62.

2. Nelson MS, Clayton BL, Moreno R. How medical school faculty regard educational research and make pedagogical decisions. Acad Med 1990;65:123-6.

3. Hylkema N, Prince CJAH, Scherpbier AJJA, Vleuten CPM van der. Is informatie over medisch onderwijs bekend en wordt het gebruikt? Bulletin Medisch Onderwijs 1999;18:74-9.

4. Visser K, Prince CJAH, Scherpbier AJJA, Vleuten CPM van der, Verwijnen GM. Student participation in educational management and organisation. Med Teach 1998;5:451-4.

\section{De auteurs}

Drs. N. Hylkema is co-assistent en was ten tijde van het onderzoek student-assistent bij het Skillslab.

C.J.A.H. Prince is huisarts in opleiding en onderzoeker bij het Skillslab.

Prof. dr. C.P.M. van der Vleuten, psycholoog, is voorzitter van de Capaciteitsgroep Onderwijsontwikkeling en Onderwijsresearch.

Prof. dr. A.J.J.A. Scherpbier, arts, is wetenschappelijk directeur van het Onderwijsinstituut.

Allen zijn verbonden aan de Faculteit der Geneeskunde van de Universiteit Maastricht.

\section{Correspondentieadres}

Prof. dr. A.J.J.A. Scherpbier, Onderwijsinstituut, Faculteit der Geneeskunde, Postbus 616, 6200 MD Maastricht, e-mail: a.scherpbier@oifdg.unimaas.nl.

\section{Summary}

Introduction: Medical education is moving ahead rapidly. Curricula are being revised everywhere. There are medical educational conferences and courses organised and professional journals published. Internationally, there are calls for the educational debate to become more evidence-based. We were interested to learn how much importance is attached to the outcomes of educational research by those involved in educational policymaking in the Dutch Faculties of Medicine and how they keep abreast of developments.

Methods: A postal survey was conducted among 326 persons in posts at policymaking levels within the eight Dutch Faculties of Medicine. They received a reminder after four weeks.

Results: The response was $74.2 \%$. Courses organised locally at the medical school are well attended. National and international conferences are attended less frequently. Medical education journals are rarely read and journal titles were unfamiliar to many respondents. The importance of educational research is generally recognised.

Conclusion: Better use can and must be made of the available resources for keeping abreast of recent developments in medical education. (Hylkema N, Prince CJAH, Vleuten CPM van der, Scherpbier AJJA. Are outcomes of medical educational research used in medical educational practice? Dutch Journal of Medical Education 2001;20(1):2-7.) 